\title{
Effectiveness of Aqueous and Alcoholic Extracts of Barberry, Jujube, and Saffron Against Oxidative Stress in Streptozotocin-Induced Diabetic Rats
}

\author{
Maryam Valavi, ${ }^{1}$ Fateme Mezginejad, ${ }^{1}$ Fatemeh Haghighi, ${ }^{2}$ Mina Hemmati, ${ }^{3,}{ }^{*}$ Asghar Zarban, ${ }^{4}$ and \\ Elham Rabiei Gask ${ }^{2}$ \\ ${ }^{1}$ Student Research Committee, Birjand University of Medical Sciences, Birjand, Iran \\ ${ }^{2}$ Department of Pathology, Faculty of Medicine, Birjand University of Medical Sciences, Birjand, Iran \\ ${ }^{3}$ Birjand CardioVascular Disease Research Center, Birjand University of Medical Sciences, Birjand, Iran \\ ${ }^{4}$ Biochemistry Department, Faculty of Medicine, Birjand University of Medical Sciences, Birjand, Iran \\ "Corresponding author: Mina Hemmati, Ph.D, Associate Professor in Clinical Biochemistry Department of Biochemistry, Faculty of Medicine, Birjand University of Medical \\ Sciences, Birjand, Iran. Tel: +98-5632381541, Fax: +98-5632393004, E-mail: minahemmati@bums.ac.ir
}

Received 2016 May 31; Revised 2016 June 13; Accepted 2016 June 28.

\begin{abstract}
Background: The use of herbal medicine has recently increased because of its effectiveness, limited side effects, and easy accessibility. In the present study, we investigated the antioxidant properties and diabetes treatment potential of 3 medicinal plants of barberry, saffron, and jujube. Methods: In the present study, 65 diabetic male Wistar rats were randomly divided into 13 groups. Groups 1 to 6 included diabetic rats that received hydroalcoholic extracts and groups 7 to 12 received aqueous extracts of the plants. The rates in Group 13 were diabetic controls, and 5 male Wistar rats were used as non-diabetic controls. Total antioxidant capacity, lipid peroxidation, radical scavenging activity, and fasting blood glucose were measured at the end of the 21st day of the treatment.

Results: Hydroalcoholic and aqueous extracts of the plants decreased malondialdehyde, and in contrast, increased total antioxidant levels (P $\leq$ 0.05). Increased levels of insulin and decreased levels of FBG in all treated groups were observed, which were notable for hydroalcoholic extract of saffron.

Conclusions: The antioxidant properties of the plants, especially saffron and jujube, lead to the regeneration of pancreatic islet and probably increase insulin release in these treatment groups; and, the plants exert their beneficial antidiabetic effects because of their antioxidant potential.
\end{abstract}

Keywords: Diabetes, Oxidative Stress, Jujube, Saffron, Barberry

\section{Background}

Diabetes is the most common endocrine disorder that originates from abnormalities in insulin secretion, insulin action, or both. The control of diabetes is critical because its prevalence is increasing and it has a number of complications (1).

Although medicinal plants and their derivatives have been discussed in traditional medicine for the treatment of diabetes mellitus and its complications, no systematic studies have been published on the effectiveness of many of them (2). The use of herbal remedies for diabetes is increasing because of their effectiveness, limited side effects, easy access, and inexpensiveness. More than 1200 types of plants have been used to treat diabetes, and more than half of them come from traditional medicine (3). The jujube plant (Ziziphus jujuba) is a shrub that belongs to the Rhamnaceae family (4). It has historically been used as an antidiabetic agent. Jujube fruit contains flavonoids along with sterols, tannins, and saponins (5). Saffron (Crocus sativus) is a small herb belonging to the Iridaceae family (6). The extract of this plant contains alpha crocetin, water-soluble carotenoids, crocins, and safranal (7). The crocin, crocetin, and safranal in saffron have free radical scavenging potential and it is possible that saffron ingredients could prevent oxidative stress and development of Type 1 diabetes (8).

Barberry (Berberis vulgaris) is a traditional herbal medicine for Type 2 diabetes. All parts of this plant contain berberine alkaloids, berbamine, and oxyacanthine; its main alkaloid is berberine, which has antioxidant, antiinflammatory, hypoglycemic, and hypolipidemic properties (9).

Oxidative stress plays a pivotal role in pathogenesis of diabetes. Thus, to assess antioxidant potential and diabetes management of barberry, jujube, and saffron extracts, we considered the changes in fasting blood sugar, insulin, and pancreatic beta cells count. We also assessed oxidative stress markers in streptozotocin-induced diabetic rats treated by hydroalcoholi and aqueous extracts of the medicinal plants. 


\section{Methods}

\subsection{Laboratory Animals}

In this interventional study, 70 adult male Wistar rats (200 - 220 g) were used. Diabetes was induced using a 60 $\mathrm{mg} / \mathrm{kg}$ intraperitoneal injection of streptozotocin (SigmaUSA). Rats with glucose levels of $300 \mathrm{mg} / \mathrm{dL}$ were considered diabetic. Groups 1 to 6 included diabetic rats receiving oral administrations of alcoholic extracts at doses of 25 and $100 \mathrm{mg} / \mathrm{kg}$. Groups 7 to 12 administered aqueous extracts at doses of 25 and $100 \mathrm{mg} / \mathrm{kg}$. Groups 13 and 14 were the untreated diabetic and healthy control groups, respectively. At the end of the experimental period (21 d), the blood samples were taken from the heart, serum was obtained, and kept at $-20^{\circ} \mathrm{C}$ until further testing (10). All experiments on rats were performed according to the principles of the Ethics Committee of the University.

\subsection{Preparation of Aqueous and Alcoholic Extracts}

Barberry roots, saffron stigma, and jujube fruits were used to prepare the extracts. The herbal powder was mixed with distilled water at a ratio of 1:9 and boiled for 10 to 15 minutes to prepare the extract. After centrifuging at 2000 rpm for 3 minutes, the supernatant was filtered and dried at $37^{\circ} \mathrm{C}$. The dried extracts were stored until further use (11). Voucher specimen for saffron, jujube, and barberry were preserved in the Herbarium of Birjand University. To prepare the alcohol extract, each plant powder was soaked in $500 \mathrm{ml}$ of $80 \%$ ethanol for 3 days. After filtration of the solute, the extract was thoroughly dried using a rotary evaporator in a vacuum at $45^{\circ} \mathrm{C}(12)$.

\subsection{Measurement of Oxidative Stress Status in the Experimental Groups}

Malondialdehyde (MDA) level as an indicator of oxidative stress (13) was measured using the thiobarbituric acid reactive substances (TBARS) method (14). The intensity of the colored complex was monitored at $532 \mathrm{~nm}$.

The FRAP assay was used to evaluate the total antioxidant power according to procedures of Benzie and Strain (15). Antioxidant power in the samples reduced ferric to ferrous iron at low $\mathrm{pH}$ levels and led to the formation of a colored ferrous-tripyridyltriazine complex. The intensity of the colored complex was monitored at $593 \mathrm{~nm}$.

\subsection{DPPH Radical-Scavenging Activity}

Effect of the herb extracts on 1, 1-diphenyl-2picrylhydrazyl (DPPH) free radical was measured based on a previous study (16). The percentage of DPPH free radical scavenges ability of the 3 medicinal plants was reported as $\%$.

\subsection{Determination of Flavonoids}

The percentage of flavonoids was measured using rutin as a reference (17). According to this procedure, plant extract solution and rutin solution (as a reference solution) and aluminum trichloride solution were mixed. The absorbance was read at $415 \mathrm{~nm}$ after 40 minutes at $20^{\circ} \mathrm{C}$. The percentage of flavonoids in plant extracts was calculated by the following formula: $\mathrm{X}=(\mathrm{A} \times \mathrm{mo} \times 100 \times 10) /(\mathrm{Ao}$ $\times \mathrm{m} \times 100)$, where $A$ is the absorbance of extract, Ao the absorbance of rutin; $m$ the weight of pure extract $(\mathrm{g})$, and mo the weight of rutin $(\mathrm{g})$.

\subsection{Determination of Flavonols}

Series of reference rutin solutions containing 0.05, 0.1, $0.15,0.2,0.3,0.4$, and $0.5 \mathrm{mg} / \mathrm{mL}$ of rutin were prepared. Rutin solution was mixed with aluminum trichloride solution; absorbance was read at $440 \mathrm{~nm}$ after 2.5 hours at $20^{\circ} \mathrm{C}$, and the calibration curve was drawn. The percentage of flavonols was calculated by the following formula: $\mathrm{X}=(\mathrm{C} \times \mathrm{V} \times 100) /(\mathrm{m} \times 100)$, where $\mathrm{C}$ is the concentration of rutin, determined form the calibration curve $(\mathrm{mg} / \mathrm{mL}), \mathrm{V}$ the volume of plant extract $(\mathrm{mL})$, and $\mathrm{m}$ the weight of pure plant extract (g) (17).

\subsection{Measurement of Fasting Blood Glucose and Insulin}

Fasting blood glucose (FBG) in different groups was measured as specified by the supplier kit (Pars Azmun, Iran) based on the photometric method. ELISA kits from Glory science (Thailand) were used to detect insulin levels.

\subsection{Histological Studies}

The number of pancreatic islets in response to the medicinal plants was calculated. After paraffin embedding, sections were prepared and stained by hematoxylin and eosin. Total number of islet cells in each section was counted under light microscope.

\subsection{Statistical Analysis}

Data were presented as mean \pm SD. Using SPSS statistical software Version 16; the data were statistically analyzed by one-way ANOVA. The level of statistical significance was set at $\mathrm{P} \leq 0.05$. The ethics committee of Birjand University of Medical Sciences, Birjand, Iran, approved the study (approval code (Ir.bums.REC.1394.402)). 


\section{Results}

In the present study, we found that MDA levels were higher in the diabetic control group. Figures 1 and 3 revealed that MDA levels were lower for groups receiving hydroalcoholic and aqueous extracts. Saffron, jujube, and barberry could significantly decrease serum levels of MDA (Figures 1 and 3). As displayed in Figure 1, the administration of hydroalcoholic extract of saffron notably decreased lipid peroxidation in a dose-dependent manner.

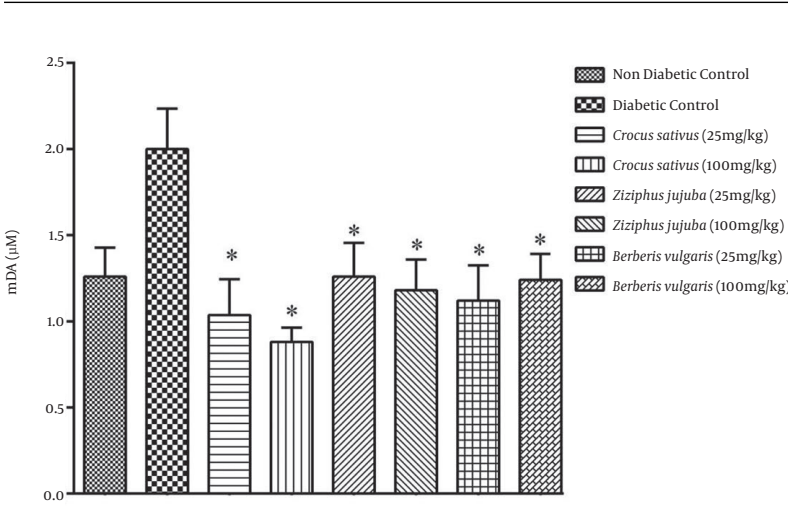

Figure 1. Comparison of serum MDA in groups receiving hydroalcohol extracts. Data shown is mean $\pm S D(n=5)$. $\left({ }^{*}\right)$ denotes significant difference in MDA levels in treated groups $(\mathrm{P} \leq 0.05)$ compared with control diabetic group.

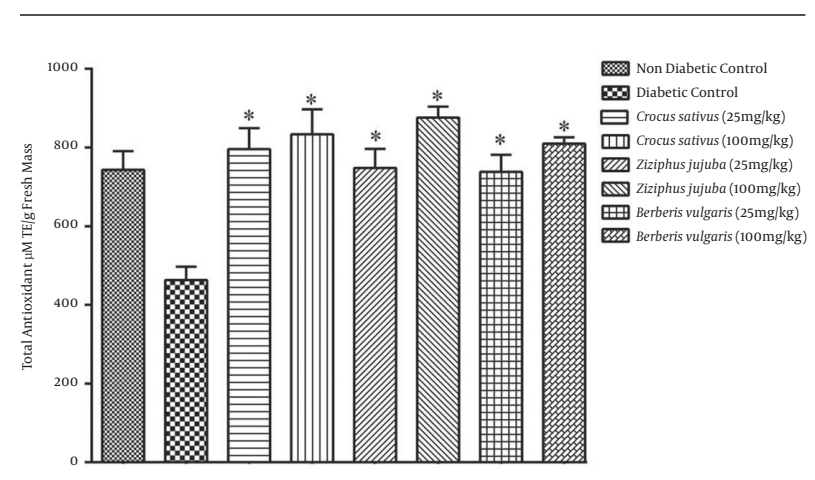

Figure 2. Mean total serum antioxidant levels in groups receiving hydroalcohol extract. Data shown is mean $\pm S D(n=5)$. $\left({ }^{*}\right)$ denotes a significant difference in total antioxidant total $(\mathrm{P} \leq 0.05)$ compared with control diabetic group.

Antioxidant activity was higher in groups receiving hydroalcoholic extracts compared with aqueous extract groups (Figures 2 and 4). The results of DPPH assay showed (Figure 5) that hydroalcoholic extracts of saffron and jujube exhibited greater free radical scavenging activity than the aqueous extracts. Total phenolic content assay revealed higher level of flavonoids and flavonol in hydroalcoholic extract (Table 1). Among the 3 medicinal plants, hydroalcoholic extract of saffron had the highest phenolic content.

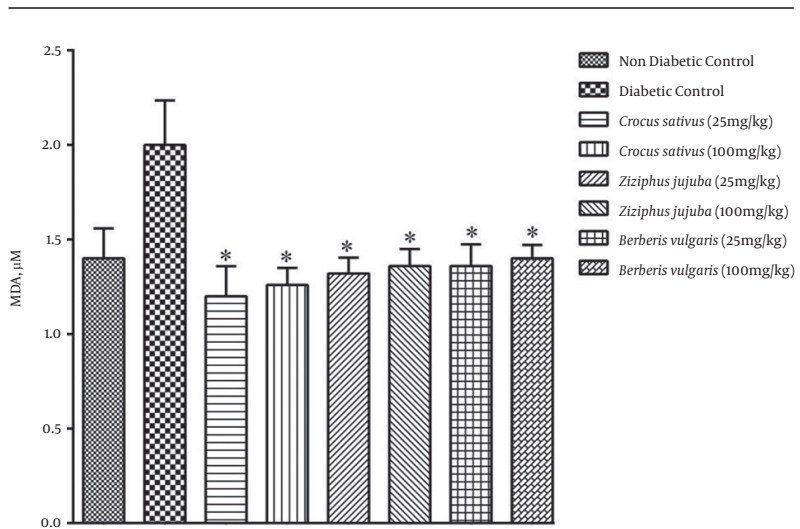

Figure 3. Comparison of mean MDA serum level in groups receiving aqueous extract. Data shown is mean $\pm \mathrm{SD}(\mathrm{n}=5)$. $\left(^{*}\right)$ denotes a significant difference in MDA $(\mathrm{P} \leq 0.05)$ compared with control diabetic group.

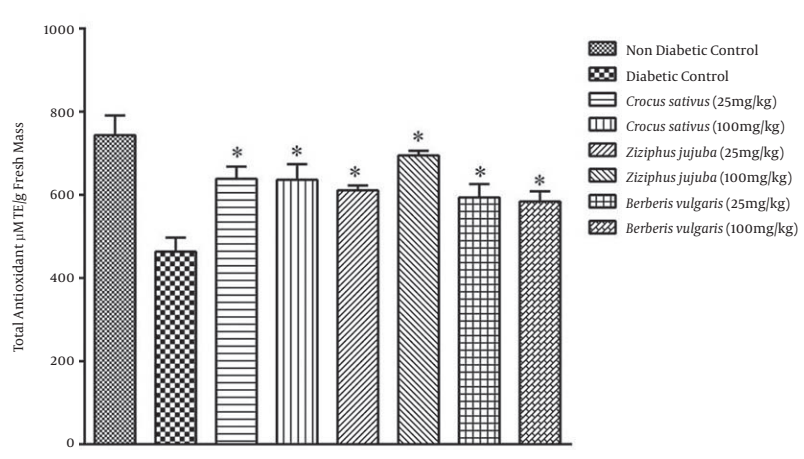

Figure 4. Comparison of mean antioxidant serum level in groups receiving aqueous extracts. Data shown is mean $\pm S D(n=5) .\left({ }^{*}\right)$ denotes a significant difference in total antioxidant total $(\mathrm{P} \leq 0.05)$ compared to control diabetic group.

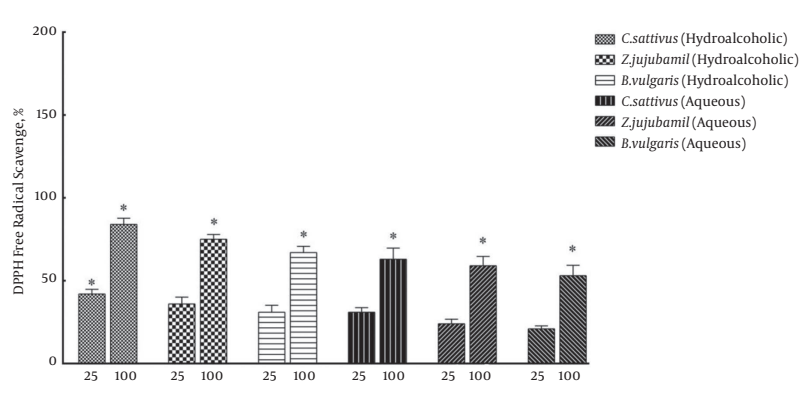

Figure 5. Percentage of DPPH radical quenching activity of various concentrations of alcoholic and aqueous extracts of three medicinal plants. Data are expressed as mean $\pm S D(n=3)$ and the histograms marked with asterisk are significantly different at $\mathrm{P} \leq 0.05$ (one way ANOVA and Duncan test).

Serum levels of FBG, insulin, and number of pancreatic islets in all groups were summarized in Tables 2 and 3. Results indicated that oral administration of the extracts lead 
Table 1. The Amounts of Phenolic Compounds, Flavonoids and Flavonols in the Extracts of Three Medicinal Plants (GAE, Gallic Acid Equivalents; RE, Rutin Equivalents)

\begin{tabular}{|c|c|c|c|}
\hline Extracts & $\begin{array}{l}\text { Total Amount of Phenolic Compounds } \\
\text { (mg/g GAE) }\end{array}$ & Amount of Flavonoids (mg/g RE) & Amount of Flavonols (mg/g RE) \\
\hline Aqueous extract of $C$. Sativus & $16.7^{\mathrm{a}}$ & 6.3 & 0.91 \\
\hline Hydroalcoholic extract of C.sativus & $18.9^{\mathrm{a}}$ & $8.8^{\mathrm{a}}$ & $1.6^{\mathrm{a}}$ \\
\hline Aqueous extract of Z.jujuba & 15.3 & 6.1 & 1.1 \\
\hline Hydroalcoholic extract of Z.jujuba & 18.2 & $9.2^{\mathrm{a}}$ & 1.4 \\
\hline Aqueous extract of B.vulgaris & 12.7 & 5.04 & 0.41 \\
\hline Hydroalcoholic extract of B.vulgaris & 14.4 & 6.9 & 0.56 \\
\hline
\end{tabular}
extract.

to increase in the insulin level and decrease in FBG level (Table 2). The treatment with the hydroalcoholic extracts of the medicinal plants increased the number of islets up to 2 to 3 folds, particularly $100 \mathrm{mg} / \mathrm{kg}$ dosage of saffron showed a notable effect.

\section{Discussion}

The results of the present study revealed that hydroalcoholic extracts of barberry, saffron, and jujube could improve diabetes by influencing lipid peroxidation and changing the antioxidant capacity. Based on the literature, saffron could decrease MDA level and increase total antioxidant capacity in diabetic treated groups compared to the untreated group $(8,18)$.

Saffranal is a major aldehyde component of saffron and has been seen to have effective antioxidant activity in vivo (19). It may also be responsible for improving hyperglycemia, hyperlipidemia, and oxidative stress in diabetic rats induced by streptozotocin (19).

Further evidence comes from studies such as Abd ElWahab et al., who showed that ethanol extracts of barberries increased the activity of antioxidant enzymes in a dosedependent manner (20).

Barberry has scavenging effect on free radicals, especially targeting against hydroxyl radicals and DPPH (21). Similar dose-dependent effects of hydroalcoholic extracts of jujube, saffron, and barberry were also seen in the present study.

According to the result of Murugesh et al., liver of rats who fed on barberries showed antioxidant enzyme activity higher than control groups (22). Further beneficial effects of barberry on the livers of diabetic rats and overall improvement of diabetic complications were also assessed by Singh and Kakkar (23).

The results of the present study revealed that MDA levels in groups receiving jujube have markedly decreased. In- terestingly, total antioxidant levels in groups receiving hydroalcoholic and aqueous extract of jujube were greater than those of all other groups. Jujube has increased total antioxidant capacity in a dose-dependent manner, and this effect was notable for hydroalcoholic extract. A protective effect of jujube was also seen in earlier studies. They found that jujube extract decreased levels of TBARS, and they also found a considerable increase in antioxidant enzyme activity in animals receiving jujube extract (24).

Previous studies found that carotenoids inhibit free radicals-mediated lipid peroxidation (25). It is possible that jujube fruit extract, with remarkable amounts of carotenoid, prevents the accumulation of hydrogen peroxide by increasing the activity of enzymes such as glutathione peroxidase (26). Flavonoids in plants can decrease oxidative stress by increasing antioxidant enzymes and correspondingly decreasing lipid peroxidation (27).

The results of the current study showed higher level of flavonoids and flavonol in hydroalcoholic extracts compared with aqueous extract. Among the three medicinal plants, hydroalcoholic extract of saffron had the highest phenolic content. The results of DPPH assay revealed that hydroalcoholic extracts of saffron and jujube exhibited greater free radical scavenging activity than aqueous extracts.

Phenolic and flavonoid compounds are important because of their ability to serve as antioxidants (28). The antioxidant activity in saffron stigma might be attributed to the presence and synergistic effects of phenolic and flavonoid compounds besides any other active compounds present (29). Siddhuraju and Becker (30) noted that the plants with higher levels of total phenolics and flavonoids exhibited greater reducing power activity. The results of the current study showed that the ethanolic extracts appeared to be more effective than aqueous extract in reducing power activity and DPPH scavenging activity, which might be explained by the higher total flavonoid 
Table 2. Effect of Hydroalcoholic Extracts of Saffron, Jujube and Barberry on STZ-Diabetic Rats

\begin{tabular}{|c|c|c|c|}
\hline Experimental Groups $^{\mathrm{a}}$ & Fasting Blood Glucose $(\mathrm{mg} / \mathrm{dL})$ & $\operatorname{Insulin}(\mathbf{m M} \mathbf{M} \mathbf{m L})$ & Number of Pancreatic Islets $\left(\mathrm{cm}^{-2}\right)$ \\
\hline Non diabetic control & $95 \pm 9.4^{\mathrm{Ab}}$ & $12 \pm 0.5^{\mathrm{A}}$ & $43 \pm 3.5^{\mathrm{A}}$ \\
\hline Diabetic control & $458 \pm 11.6^{\mathrm{B}}$ & $6.3 \pm 0.12^{\mathrm{B}}$ & $13 \pm 1.8^{\mathrm{B}}$ \\
\hline Crocus sativus ( $25 \mathrm{mg} / \mathrm{kg}$ ) & $210 \pm 7.5^{\mathrm{C}}$ & $8.9 \pm 0.2^{\mathrm{A}}$ & $24 \pm 2.4^{\mathrm{C}}$ \\
\hline Crocus sativus (100 mg/kg) & $142 \pm 5.6^{A}$ & $10.4 \pm 0.14^{\mathrm{A}}$ & $31 \pm 3.2^{\mathrm{A}}$ \\
\hline Ziziphus jujuba (25 mg/kg) & $205 \pm 7.4^{C}$ & $8.1 \pm 0.09^{\mathrm{B}}$ & $22 \pm 2.1^{\mathrm{C}}$ \\
\hline Ziziphus jujuba (100 mg/kg) & $136 \pm 6.5^{\mathrm{A}}$ & $10.1 \pm 0.13^{A}$ & $31 \pm 2.8^{\mathrm{A}}$ \\
\hline Berberis vulgaris ( $25 \mathrm{mg} / \mathrm{kg}$ ) & $245 \pm 9.4^{\mathrm{C}}$ & $7.2 \pm 0.05^{\mathrm{B}}$ & $19 \pm 1.9^{\mathrm{C}}$ \\
\hline Berberis vulgaris (100 mg/kg) & $165 \pm 8.5^{\mathrm{A}}$ & $9.3 \pm 0.11^{\mathrm{A}}$ & $29 \pm 2.6^{\mathrm{A}}$ \\
\hline
\end{tabular}

${ }^{\mathrm{a}}$ For details of experimental conditions see the text.

${ }^{b}$ Data are expressed as means $\pm S D$ of five rats in each group. In each column, figures bearing different superscripts are significantly different at $\mathrm{P} \leq 0.05$ (one way ANOVA and Duncan test).

Table 3. Effect of Aqueous Extracts of Saffron, Jujube and Barberry on STZ-Diabetic Rats

\begin{tabular}{|c|c|c|c|}
\hline Experimental Groups $^{\mathrm{a}}$ & Fasting Blood Glucose $(\mathrm{mg} / \mathrm{dL})$ & Insulin $(\mathbf{m M} / \mathbf{m L})$ & Number of Pancreatic Islets $\left(\mathrm{cm}^{-2}\right)$ \\
\hline Non diabetic control & $95 \pm 9.4^{\mathrm{Ab}}$ & $12 \pm 0.5^{\mathrm{A}}$ & $43 \pm 3.5^{\mathrm{A}}$ \\
\hline Diabetic control & $458 \pm 11.6^{\mathrm{B}}$ & $6.3 \pm 0.12^{\mathrm{B}}$ & $13 \pm 1.8^{B}$ \\
\hline Crocus sativus ( 25 mg/kg) & $210 \pm 7.5^{\mathrm{C}}$ & $8.9 \pm 0.2^{\mathrm{A}}$ & $24 \pm 2.4^{\mathrm{C}}$ \\
\hline Crocus sativus (100 mg/kg) & $142 \pm 5.6^{A}$ & $10.4 \pm 0.14^{\mathrm{A}}$ & $31 \pm 3.2^{\mathrm{A}}$ \\
\hline Ziziphus jujuba (25 mg/kg) & $205 \pm 7.4^{\mathrm{C}}$ & $8.1 \pm 0.09^{B}$ & $22 \pm 2.1^{\mathrm{C}}$ \\
\hline Ziziphus jujuba (100 mg/kg) & $136 \pm 6.5^{\mathrm{A}}$ & $10.1 \pm 0.13^{\mathrm{A}}$ & $31 \pm 2.8^{\mathrm{A}}$ \\
\hline Berberis vulgaris (25 mg/kg) & $245 \pm 9.4^{\mathrm{C}}$ & $7.2 \pm 0.05^{\mathrm{B}}$ & $19 \pm 1.9^{\mathrm{C}}$ \\
\hline Berberis vulgaris (100 mg/kg) & $165 \pm 8.5^{\mathrm{A}}$ & $9.3 \pm 0.11^{\mathrm{A}}$ & $29 \pm 2.6^{\mathrm{A}}$ \\
\hline
\end{tabular}

${ }^{a}$ For details of experimental conditions see the text.

${ }^{b}$ Data are expressed as means \pm SD of five rats in each group. In each column, figures bearing different superscripts are significantly different at $\mathrm{P} \leq 0.05$ (one way ANOVA and Duncan test).

content of the ethanolic extract.

Improvement of pancreatic beta cells by saffron was seen in Mohajeri et al. research (31). Histological analyses of pancreatic beta cells in diabetic rats showed that their pancreatic tissue was similar to normal tissue after treatment with saffron extract.

Data obtained from the current study revealed that the medicinal plants, particularly saffron, had a protective effect in diabetic animals. Hypoglycemic and pancreatic regeneration effects of the medicinal plants are in line with the antioxidant capacity of these plants.

The results of the present study indicated that barberry, jujube, and especially saffron extract, have notable antioxidant and hypoglycemic effects and may help improve diabetic complications. These beneficial effects could be taken into consideration when designing new drugs. Conducting further experimental and clinical investigation is required to determine the effective dosage of the hydroalcoholic extracts of saffron in clinical practice.

\section{References}

1. Smith JS. Antidiabetic drugs medical library. 2003 ;5:5-6.

2. Shapiro K, Gong WC. Natural products used for diabetes. J Am Pharm Assoc. 2002;42(2):217-26.

3. Gupta RK, Kesari AN, Murthy PS, Chandra R, Tandon V, Watal G. Hypoglycemic and antidiabetic effect of ethanolic extract of leaves of Annona squamosa L. in experimental animals. J Ethnopharmacol. 2005;99(1):75-81. doi:10.1016/j.jep.2005.01.048. [PubMed:15848023].

4. San B, Yildirim AN, Polat M, Yildirim F. Mineral composition of leaves and fruits of some promising Jujube (Zizyphus jujuba miller) genotypes.. Asian J Chem. 2009;21(4):2898.

5. Ebrahimimd S, Ashkani-Esfahani S, Poormahmudibs A. Investigating the efficacy of zizyphus jujuba on neonatal jaundice. Iran J Pediatr. 2011;21(3):320-4. [PubMed: 23056808].

6. Agha-Hosseini M, Kashani L, Aleyaseen A, Ghoreishi A, Rahmanpour $\mathrm{H}$, Zarrinara AR, et al. Crocus sativus L. (saffron) in the treatment of premenstrual syndrome: a double-blind, randomised and placebo-controlled trial. BJOG. 2008;115(4):515-9. doi: 10.1111/j.14710528.2007.01652.x. [PubMed: 18271889]. 
7. Hosseinzadeh $\mathrm{H}$, Talebzadeh F. Anticonvulsant evaluation of safranal and crocin from Crocus sativus in mice. Fitoterapia. 2005;76(7-8):7224. doi:10.1016/j.fitote.2005.07.008. [PubMed: 16253437].

8. Peeri M, Haghigh MM, Azarbayjani MA, Atashak S, Behrouzi G. Effect of aqueous extract of saffron and aerobic training on hepatic non enzymatic antioxidant levels in streptozotocin-diabetic rats. Arch Des Sci. 2012;65(10).

9. Hemmati M, Asghari S, Zohoori E, Karamian M. Hypoglycemic effects of three Iranian edible plants; jujube, barberry and saffron: Correlation with serum adiponectin level. PakJ Pharm Sci. 2015;28(6):2095-9. [PubMed: 26639503].

10. Abdel-Zaher AO, Salim SY, Assaf MH, Abdel-Hady RH. Antidiabetic activity and toxicity of Zizyphus spina-christi leaves. $J$ Ethnopharmacol. 2005;101(1-3):129-38. doi: 10.1016/j.jep.2005.04.007. [PubMed: $16009520]$.

11. Mohebali S, Nasri S, Kamalinejhad M, Noori AS. Antinociceptive \& anti-inflammatory effects of Berberis vulgaris L. root's hydroalcoholic extract and determination of it's possible antinociceptive mechanism in male mice. J Paramed Sci. 2011;2(4)

12. Mohajeri D, Mousavi G, Mesgari M, Doustar Y, Nouri MHK. Subacute toxicity of crocus sativus l. (saffron) stigma ethanolic extract in rats. Am J Pharmacol Toxicol. 2007;2(4):189-93. doi: 10.3844/ajptsp.2007.189.193.

13. Rumley AG, Paterson JR. Analytical aspects of antioxidants and free radical activity in clinical biochemistry. Ann Clin Biochem. 1998;35 ( Pt 2):181-200. doi: 10.1177/000456329803500202. [PubMed: 9547890].

14. Yagi K. A simple fluorometric assay for lipoperoxide in blood plasma. Biochem Med. 1976;15(2):212-6. [PubMed: 962904].

15. Benzie IF, Strain JJ. The ferric reducing ability of plasma (FRAP) as a measure of "antioxidant power": the FRAP assay. Anal Biochem. 1996;239(1):70-6. doi: 10.1006/abio.1996.0292. [PubMed: 8660627].

16. Brand-Williams W, Cuvelier M-E, Berset C. Use of a free radical method to evaluate antioxidant activity. LWT-Food Sci Technol. 1995;28(1):25-30.

17. State Pharmacopoeia of USSR. . Ministerstvo Zdravochranenija CCCR. 2nd ed.;1989. p. 234.

18. Rahbani M, Mohajeri D, Rezaie A, Doustar Y, Nazeri M. Attenuation of oxidative stress of hepatic tissue by ethanolic extract of saffron (dried stigmas of Crocus sativus L.) in streptozotocin (STZ)-induced diabetic rats. African J Pharm Pharmacol. 2011;5(19):2166-73.

19. Samarghandian S, Borji A, Delkhosh MB, Samini F. Safranal treatment improves hyperglycemia, hyperlipidemia and oxidative stress in streptozotocin-induced diabetic rats. J Pharm Pharm Sci. 2013;16(2):352-62. [PubMed: 23958204].

20. Abd El-Wahab AE, Ghareeb DA, Sarhan EE, Abu-Serie MM, El Demellawy MA. In vitro biological assessment of Berberis vulgaris and its active constituent, berberine: antioxidants, anti-acetylcholinesterase, anti-diabetic and anticancer effects. BMC Complement Altern Med. 2013;13:218. doi: 10.1186/1472-6882-13-218. [PubMed: 24007270].

21. Movahedian Ataar A, Eshraghi A, Asgari S, Naderi G, Badiee A. Antioxidant Effect of Ziziphus vulgaris, Portulaca oleracea, Berberis integerima and Gundelia tournefortti on lipid peroxidation, Hb glycosylation and red blood cell hemolysis. J Med Plants. 2011;4(40)::80-8.

22. Murugesh KS, Yeligar VC, Maiti CB, Maity TK. Hepato protective and antioxidant role of Berberis tinctoria Lesch leaves on paracetamol induced hepatic damage in rats. Iranian J Pharmacol Therapeutic 2005;4:64-9.

23. Singh J, Kakkar P. Antihyperglycemic and antioxidant effect of Berberis aristata root extract and its role in regulating carbohydrate metabolism in diabetic rats. J Ethnopharmacol. 2009;123(1):22-6. doi: 10.1016/j.jep.2009.02.038. [PubMed: 19429334].

24. Taati M, Alirezaei M, Meshkatalsadat M, Rasoulian B, Kheradmand A Neamati S. Antioxidant effects of aqueous fruit extract of Ziziphus jujuba on ethanol-induced oxidative stress in the rat testes. Iranian J Veter Res. 2011;12(1):39-45.

25. Hekimoglu A, Kurcer Z, Aral F, Baba F, Sahna E, Atessahin A. Lycopene, an antioxidant carotenoid, attenuates testicular injury caused by ischemia/reperfusion in rats. Tohoku J Exp Med. 2009;218(2):141-7. [PubMed: 19478470].

26. Al-Reza SM, Bajpai VK, Kang SC. Antioxidant and antilisterial effect of seed essential oil and organic extracts from Zizyphus jujuba. Food Chem Toxicol. 2009;47(9):2374-80. doi: 10.1016/j.fct.2009.06.033. [PubMed: 19563858].

27. Amer M, El-Habibi el S, El-Gendy A. Effects of Trifolium alexandrinum extracts on streptozotocin-induced diabetes in male rats. Ann Nutr Metab. 2004;48(5):343-7. doi: 10.1159/000081664. [PubMed: 15499220]

28. Wang YC, Chuang YC, Hsu HW. The flavonoid, carotenoid and pectin content in peels of citrus cultivated in Taiwan. Food chem 2008;106(1):277-84.

29. Siddhuraju P, Mohan P, Becker K. Studies on the antioxidant activity of Indian Laburnum (Cassia fistula L.): a preliminary assessment of crude extracts from stem bark, leaves, flowers and fruit pulp. Food Chem. 2002;79(1):61-7.

30. Siddhuraju P, Becker K. Antioxidant properties of various solvent extracts of total phenolic constituents from three different agroclimatic origins of drumstick tree (Moringa oleifera Lam.) leaves. J Agric Food Chem. 2003;51(8):2144-55. doi: 10.1021/jf020444+. [PubMed: 12670148].

31. Mohajeri D, Mousavi G, Doustar Y. Antihyperglycemic and pancreasprotective effects of crocus sativus 1 . (saffron) stigma ethanolic extract on rats with alloxan-induced diabetes. J Bio Sci. 2009;9(4):30210. doi: 10.3923/jbs.2009.302.310. 